\section{Mineralogical phase change at the 670-km discontinuity}

\author{
Bernard J. Wood
}

THE boundary between the upper and lower portions of the Earth's mantle is generally taken to correspond to the worldwide seismic discontinuity at $670 \mathrm{~km}$ depth, at which the seismic-wave velocity increases by a few per cent ${ }^{\prime}$ and the density of the silicate minerals increases. The simplest explanation, that the discontinuity is due to an isochemical phase transformation in a mantle of uniform composition, is disputed in the light of incompatible experimental $\mathrm{data}^{2}$ on the thermodynamic and clastic properties of high pressure phases. An alternative model is that the mantle is chemically stratified with at least one major compositional discontinuity at $670 \mathrm{~km}$ and possibly other distinct layers at shallower depths . But in a new experimental study ${ }^{4}$, Ito and Takahashi show that an isochemical transformation in $(\mathrm{Mg}, \mathrm{Fe})_{2} \mathrm{SiO}_{4}$, the dominant component of the upper mantle, has many of the properties required to explain the $67(0)-\mathrm{km}$ discontinuity. Their results would thus be consistent with both upper and lower parts of the mantle being peridotitic in composition.

The question of whether the mantle, which is convecting vigorously, is chemically layered is crucial to understanding its dynamics and its chemical and physical history. Numerical simulations $s^{5}$ indicate that even small compositional differences, equivalent to a 3-per-cent change in density, would be sufficient to inhibit convective exchange between the upper and lower mantle and hence to isolate the lower mantle from most plate-tectonic processes. Many geochemists have argued that such isolation occurs, on the grounds that it explains the apparent depletion of the source region of oceanic basalts in lithophile elements such as K, Rb, Cs, U and Th relative to the inferred composition of the bulk Earth. Modelling of the isotopic evolution of this source region implies that it corresponds to about 30 per cent of the volume of the mantle, which happens to equal the volume of the mantle above $670 \mathrm{~km}$.

Seismologically, the $670-\mathrm{km}$ discontinuity is extremely sharp, giving rise to underside primary-wave reflections that require the velocity increase to take place over at depth interval of less than $4 \mathrm{~km}$. Isochemical transformations in complex systems are generally continuous and spread out however, implying that they (annot, in general, give rise to reflections at the wavelengths of concern. Chemical sratification. on the other hand, would give a true discontinuity.

The experiments of Ito and Takahashi relate to the conditions under which $(\mathrm{Mg}, \mathrm{Fe})_{2} \mathrm{SiO}_{4}$ in the spinel structure transforms isochemically to $(\mathrm{Mg}, \mathrm{Fe}) \mathrm{SiO}_{3}$ perovskite plus $(\mathrm{Mg}, \mathrm{Fe}) \mathrm{O}$ magnesiowustite at high pressures. The authors show that the transformation is extremely sharp for compositions with upper-mantle ratios of $\mathrm{Fe}^{2+} /\left(\mathrm{Fe}^{2+}+\mathrm{Mg}\right)$ of about 0.1 and that it takes place under pressure conditions - 23 gigapascal ( $\mathrm{GPa}$ ) at $1,600{ }^{\circ} \mathrm{C}$ that closely approximate those present at the $670-\mathrm{km}$ discontinuity. For these low iron contents, the experimental data indicate that there exists a narrow transition interval of coexistence of high- and

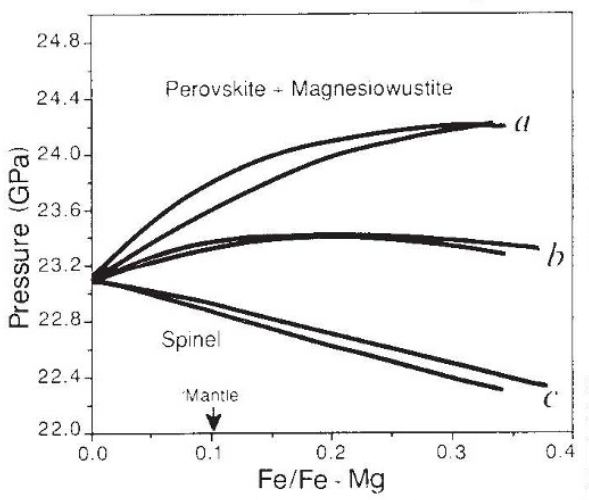

The breakdown of $(\mathrm{Mg}, \mathrm{Fe})_{2} \mathrm{SiO}_{4}$ spinel to perovskite and magnesiowustite at $1,600{ }^{\circ} \mathrm{C}$ (after ref. 4). Note that the transition interval of coexistence of all three phases has a maximum width of $0.2 \mathrm{GPa}(6 \mathrm{~km})$ if we use possible geometry $a$. The most likely geometries, however, are $b$ or $c$ which give extremely narrow transition intervals for upper-mantle values of $\mathrm{Fe}^{2+} /\left(\mathrm{Fe}^{2+}+\mathrm{Mg}\right)$.

low-pressure phases and that the transformation pressure may either increase slightly or decrease as Fe is substituted for $\mathrm{Mg}$ (see figure). But even if we assume large uncertainties in the partitioning of Fe and $\mathrm{Mg}$ between low- and high-pressure phases, it is virtually impossible to generate an interval wider than $0.2 \mathrm{GPa}$ (6-km depth interval) and values less than $0.05 \mathrm{GPa}(1.5 \mathrm{~km})$ are most likely. This leads to the unexpected conclusion that the isochemical transformation of ( $\mathrm{Mg}, \mathrm{Fe})_{2} \mathrm{SiO}_{4}$ spinel to perovskite plus oxide is essentially discontinuous and is thus capable of acting as a seismic-wave reflector.

The phase transformation may exhibit one of the main features of the $670-\mathrm{km}$ discontinuity, but is it consistent with other geophysical and geochemical data? Jeanloz and Knittle argue in another new paper" that the density of the lower mantle (known to an accuracy of about 0.5 per cent) is too high for it to be compositionally equivalent to upper mantle peridotite. From their measurements of the compressibility and thermal expansion of the perovskite phase, they infer that the lower mantle is enriched in iron relative to the upper mantle and hence, by implication, that the $670-\mathrm{km}$ discontinuity corresponds to both a chemical boundary and a phase transformation. This argument depends, however, on measurements of the thermal expansion of perovskite at low pressure, well outside the perovskite stability field ${ }^{2}$, that gave a high coefficient of thermal expansion. There is doubt about the applicability of these data, collected on a metastable phase and requiring much extrapolation in pressure and temperature, because measurements of other perovskite-like phases" yield lower thermal expansions. Adoption of a smaller thermal expansion coefficient brings the density of lower mantle into approximate agreement with that expected for peridotite compositions (C.R. Bina and P.G. Silver, personal communciation).

Although geochemical data clearly show long-term segregation of the mantle into regions distinct in isotope and traceelement evolution, there is no requirement that these reservoirs exhibit gross differences in major-element composition or that they be radially distributed above and below $670 \mathrm{~km}$ depth. Furthermore, there is increasing seismological evidence that, at plate boundaries, subducting slabs penetrate into the lower mantle ${ }^{10}$, implying that there must be at least limited chemical interchange across the $670-\mathrm{km}$ discontinuity. Although chemical stratification at $670 \mathrm{~km}$ provides a convenient explanation for the isotope data, mixing of the upper and lower mantle would also be inhibited, but not completely stopped, by a phase transition with a slightly negative pressure-temperature dependence. The transformation studied by Ito and Takahashi fulfils this requirement. Thus the new experimental data indicate that a simple phase change explains the discontinuity. Measurements of the density of perovskite plus magnesiowustite under actual lower-mantle conditions are required to refute or confirm this.

Bernard J. Wood is in the Department of Geology, University of Bristol, Bristol BS8 1RI, UK.

1. Dziewonski, A.M. \& Anderson, D.L. Phys. Earth planet. inter. 25, 297-356 (1981).

2. Knittle, E., Jeanloz, R. \& Smith, G. L. Nature 319, 214 216 (1986)

3. Anderson, D.L. \& Bass, J.D. Nature 320, 321-328 (1986)

4. Ito, E. \& Takahashi, E. J. geophys. Res. 94, $10637-$ 10646 (1989)

5. Christensen. U.R. \& Yuen, D.A. J. geophys. Res. 89 4389-4402 (1984)

6. Wasserburg G.J. \& De Paolo, D.J. Proc natn Acad. Sci. U.S.A. 76, 3594-3598 (1979)

7. Lees, A.C., Bukowinski, M.T. \& Jeanloz, R., J. geophys Res. 88, 8145-8159 (1983).

8. Jeanloz, R. \& Knittle, E. Phil. Trans. R. Soc. A328, 377 $389(1989)$.

9. Hill, R.J. \& Jackson, I. EOS 70, 475 (1989).

10. Creager, K.C. \& Jordon, T.H. J. geophys. Res. $91,3573$. $3589(1986)$. 